\title{
AN ANALYSIS OF THE VOWEL PRODUCTION OF A PROFOUNDLY HEARING IMPAIRED CHILD BEFORE AND AFTER A COCHLEAR MULTICHANNEL IMPLANT
}

\author{
Mary-Ann Kemp \\ Department of General Linguistics \\ University of Stellenbosch
}

\section{INTRODUCTION}

The benefits offered by cochlear implants to hearing impaired adults are well documented. As these prostheses have gained clinical acceptance in the rehabilitation of this population, the application of cochlear implants in the management of pre- and postlingually deafened children has increased (Owens \& Kessler 1989, Osberger 1989, Busby et al. 1989, Eisenburg et al. 1986).

The aim of the auditory prosthesis is not only to aid perception, but also to improve production. And indeed, postoperative improvements have been documented in speech perception, in speech production and in general language skills (Busby et al. 1989, Osberger 1989, Kessler 1989, Roberts et al 1988, Clark et al 1987). Osberger (1989:227) however, has found that the speech production data from children show changes which are "highly individual with large learning effects". Fine-grained analysis of longitudinal data is needed therefore, to determine the effects of the device, especially since some children do not display noticeable progress until 12 to 18 months postoperatively (Osberger 1989).

The influence of hearing impairment on speech intelligibility has received a great deal of attention in past research (Kirk \& Hill-Brown 1985, Osberger \& McGarr 1982. Ling 1976). In the analysis of speech production, both segmental and non-segmental features have been identified as contributing to the unintelligibility of deaf speakers (Osberger \& McGarr 1982). The focus in segmental phonology has been on consonant error patterns, while vowels, as in the literature on the phonological development of hearing children, are neglected (Stoel-Gammon and Herrington 1990, Pollock and Keiser 1990). 
According to Osberger (1989), the achievement of correct vowel production is particularly difficult for the hearing impaired individual because one of the primary acoustic cues that differentiates vowels occurs in the frequency region above $2000 \mathrm{~Hz}$, where many of these clients have negligible residual hearing. Furthermore, apart from lip rounding/spreading, the articulatory movements required for vowel differentiation are not clearly visible. Speakers also have limited kinesthetic feedback from vowel production (Osberger 1989).

Eisberg et al (1986) have reported a study on vowel production in children implanted with the $3 \mathrm{M} /$ House single channel cochlear implant. They conclude that children who had received the prosthesis had reduced vowel variation because the implant had not provided enough high frequency spectral information to effect a change.

In a study by Osberger (1989) subjects, 5 months after receiving the Cochlear 22channel implant, showed a noticeable change in the ability to convey vowel height and vowel space information over time. Another study by Osberger (1989) reported that a congenitally hearing impaired child who received a multichannel implant at 11 years of age, showed $40 \%$ improvement in her ability to convey vowel height, and $25 \%$ improvement in her ability to convey vowel space information. Plant and Öster (1986) also reported a shift in vowel space postoperatively. These studies amongst others therefore show that the cochlear multichannel device improves speech perception, which somehow translates to an improvement in speech production.

An important consideration in thorough phonological analysis is the reliability of auditory impressionistic transcription (AIT). Weismer (1984:30) states that if the aim of our phonological analysis is to understand the child's sound system, we should have "sensitive and reliable techniques that will permit the components of phonology to be demonstrated". Traditionally AIT provides the data for such analysis. The problems. with AIT are well documented, however (Pye et al 1988, Amorosa et al 1985, Shriberg et al 1984, Oller \& Eilers 1975). Weismer (1984) accordingly suggests that an analysis relying exclusively on AIT is unacceptable and should be supplemented by acoustic analysis.

The introductory comments have focussed on two main issues - the need to add to the database of information on the speech production of cochlear implant recipients, and the neglect of vowels in current phonological analyses. The major aim of this paper is therefore to document the changes that occurred in the vowel production of a hearing impaired child who received a cochlear multichannel implant at Tygerberg Hospital, 
South Africa. It was hypothesised that the child's vowel system pre-implantation would differ markedly from the local dialect target vowel system, and that the child's vowel system would undergo post-implantation changes and in so doing would gradually approximate to the target system. A secondary aim was concerned with preliminary investigation of appropriate analysis procedures for such data. The analysis involved two phases: firstly, the establishment of a reference vowel system for AIT and acoustic analysis that is representative of the local dialect, and secondly, a comparison of analysis procedures in order to comment on the clinical benefit of the procedures.

\section{METHOD}

\section{Subject}

The subject of this descriptive case-study is a profoundly hearing impaired, Englishspeaking boy, K, who received a Cochlear 22-channel implant in September 1988 at the age of 9 years 7 months. The cause of his congenital hearing loss is unknown. At the age of 8 months he was fitted bilaterally with ear-level hearing aids; and at the same time, oral/aural rehabilitation was initiated. Despite $\mathrm{K}$ 's remarkable progress in speech and language skills, it was clear that he received no discernible benefit from conventional amplification. After extensive audiological, psychological and speech and language evaluation, he was considered as a candidate for a cochlear implant. The 22electrode array was implanted in K's right ear. His progress was monitored by a battery of tests at 6 months and 1 year postoperatively.

\section{Data collection}

In order to investigate the changes in $\mathrm{K}$ 's vowel production, the word lists of Hodson (1986) and McGarr (1986) were used as stimulus words (see Appendices 1 and 2). Each of the two random word lists was presented at three different stages: preoperatively, 6 months postoperatively and 1 year postoperatively. Each session was audio- and videotaped. 


\section{Analysis procedures}

The analysis of the data was performed in the following way:

(i) Auditory Impressionistic Transcription (AIT): All K's productions of the stimulus words were transcribed phonetically under the supervision of a phonetician. The reference system for comparative purposes was based on the transcriptions of the productions of the same word lists by a hearing speaker of South African English (SAE).

(ii) Acoustic analysis: The productions of the McGarr stimulus words by $\mathrm{K}$ and by the hearing speaker were subjected to spectrographic analysis in order to determine the Formant 1 and Formant 2 values of the target system, of K's preoperative system and of K's systems at 6 months and 1 year postoperatively. Broad-band spectrograms with a filter width of $450 \mathrm{~Hz}$ were used. The formants were determined by measuring the central formant value of the spectrogram. Comparisons were made to determine whether $\mathrm{K}$ 's formants changed from the preoperative status in such a way as to approximate to those of the target system.

(iii) Analysis of the vowels according to Reid's Procedure for Assessing Vowels (unpublished): The vowels recorded in the AIT were used for two purposes. On the one hand they served as the database when K's vowel productions were analysed with a view to identifying the relationship between $\mathrm{K}$ 's vowel system and the adult target system. On the other hand the vowels recorded in the AIT were also used as a source of information about $\mathrm{K}$ 's error patterns and contrastive use of vowel phones over the period specified.

\section{RESULTS AND DISCUSSION}

The results will be presented in the order in which the corresponding analysis procedures were outlined above: (i) results of the AIT of the vowels of the Hodson and McGarr words, (ii) results of the spectrographic analysis of the McGarr words and (iii) results of the analysis of the vowels according to Reid's assessment procedure (unpublished). 
Appendices 1 and 2 provide a summary of the vowel transcriptions. Accurate, consistent transcription of vowels is notoriously difficult. For example, features such as breathiness and nasality, which are typical of the speech of hearing impaired individuals, tend to cloud transcribers' judgements. This could account for the variable perceptions and transcriptions of $\mathrm{K}$ 's vowel realisations in the primary analysis of the data. Improvements at the AIT level are less conspicuous than the results of the instrumental and phonological analyses would seem to show. The contribution, if any, of improved suprasegmental abilities to improved intelligibility was not investigated. Since it is well documented that the information which cochlear implants provide is largely suprasegmental, it is speculated that the AITs of $\mathrm{K}$ 's vowels were affected by the improvements in K's realisation of suprasegmental features (Rosen et al 1989, Clark et al 1987, Eisenberg et al 1986). There are also some productions that seem idiosyncratic: they appear neither to be phonologically governed nor to represent clear trends. As was suggested by Weismer (1984), AIT may miss contrasts which, though important, only become obvious with supplementary acoustic analysis. Butcher (1982:69) maintains that distinctions such as those specified by the cardinal vowel system are "totally spurious in the light of the degree of latitude demonstrated both in the production of the cardinal vowels by phoneticians and in their (placing) of sounds in reference to them". It is important to point out that while some degree of precision was achieved in the present investigation, the transcriptions largely assign class membership rather than attempt to record every detailed articulatory nuance.

Despite these difficulties, the phonetic transcriptions reveal several error patterns. The first of these concerns vowel length. K's vowels show both exaggerated length and excessive shortening of monophthongs and diphthongs, although the shortening is less prevalent. Tables 1 and 2 show examples of this phenomenon. 


\begin{tabular}{|c|c|c|c|}
\hline Gloss & Preoperatively & $\begin{array}{l}\text { Postoperatively } \\
6 \text { months }\end{array}$ & $\begin{array}{l}\text { Postoperatively } \\
1 \text { year }\end{array}$ \\
\hline 1. Keep & {$\left[k^{n i}: p^{h}\right]$} & {$\left[k^{h} \tilde{i}: p\right]$} & {$\left[\int i: p\right]$} \\
\hline 2. read & & {$[v i: d]$} & {$\left[v i j i t^{h}\right]$} \\
\hline 3. piece & & {$\left[\mathrm{pi}: \mathrm{s}^{2}\right]$} & [ pi:s] \\
\hline 4. deep & [si:p ] & [ $\sigma i: p]$ & {$\left[f^{v i: p]}\right.$} \\
\hline 5. food & {$\left[f_{t:}{ }^{\theta}\right]$} & [fus: ] & {$\left[f^{i} u:\right]$} \\
\hline 6. teeth & {$[t i: \theta]$} & {$\left[t i: \theta_{t}\right]$} & {$[t \tilde{\imath}: \theta]$} \\
\hline 7. $\operatorname{man}$ & [m $\widetilde{3}$ en] & [m乏: ] & {$[m \widetilde{3}: n]$} \\
\hline 8. beach & {$\left[b^{i} v \theta\right]$} & {$\left[b^{n} i: t\right]$} & {$[\vee \widetilde{1:}]$} \\
\hline 9. fall & {$\left[f_{\phi w \partial \mid}\right]$} & {$[\theta 031]$} & {$\left[\begin{array}{lll}f o l & ]\end{array}\right.$} \\
\hline 10. more & {$\left[m o^{v}\right]$} & [mo3:] & [mo ] \\
\hline
\end{tabular}

Table 1: Examples of exaggerated length in monophthongal vowels in $\mathrm{K}$ 's productions of McGarr words

\begin{tabular}{|c|c|c|c|}
\hline Gloss & Preoperatively & $\begin{array}{l}\text { Postoperatively } \\
6 \text { months }\end{array}$ & $\begin{array}{l}\text { Postoperatively } \\
1 \text { year }\end{array}$ \\
\hline 1. have & [ hif ] & [ $\left.h \varepsilon_{\Lambda} f\right]$ & {$\left[\begin{array}{lll}\varepsilon f & ]\end{array}\right.$} \\
\hline 2. book & {$[b \underset{x}{b} \times]$} & {$[b$ əa>k $k]$} & [ bok ] \\
\hline 3. with & {$\left[w \hat{\partial} \theta^{t}\right]$} & {$\left[w \hat{\lambda} \theta^{t}\right]$} & {$\left[w \hat{\partial} \theta^{t}\right]$} \\
\hline
\end{tabular}

Table 2: Examples of excessive shortening of vowels in $\mathrm{K}$ 's productions of McGarr words 
While the target pronunciations of these vowels in SAE are perceived as shorter than the received pronunciation (RP) counterparts (Wells, 1982), K's productions are regarded as abnormally long even by RP standards. It is possible that increasing the length of the vowel allows him to assess the placement of the articulation more accurately due to increased feedback. However that may be, a definite result of $\mathrm{K}$ 's exaggeration of vowel lengths is a diphthongisation of his monophthongs.

An interesting feature of $\mathrm{K}$ 's production of the high front vowel / $\mathrm{i}:$ / postoperatively is the way he oscillates between the target itself and an approximation to the target, namely /j/ (a palatalised speech sound and, hence, closer). The oscillation highlights the difficulty $\mathrm{K}$ has in controlling the articulation of a sustained vowel.

The second error pattern concerns nasality. This is apparent throughout the transcriptions. Hypernasality, well documented in the speech of the hearing impaired, is also considered to provide additional proprioceptive feedback in production.

Close examination of the AIT and comparisons between pre- and postoperative evaluations indicate some improvements. There is a gradual approximation to target phonemes represented by items such as $/ \mathrm{b} / \mathrm{in} \underline{\operatorname{dog}} / \mathrm{J} / \mathrm{in}$ more and $/ \mathrm{e} /$ in red.

\section{(ii) Acoustic analysis of the McGarr wonds}

The F1/F2 plots are presented in Figures 1-4. It must be stressed that the formant values represent a single measurement, which has implications for generalisation. The most striking features of the F1/F2 plots are, firstly, the difference between the configuration for the target vowels and the preoperative vowels and, secondly, the immediate difference between the formants of the preoperative and postoperative vowel productions. The graph for the preoperative formants shows that while isolated vowel formants corresponding to the phonemes $/ \mathrm{e} /,|\varepsilon /,| \mathrm{l} /$ and $/ \mathrm{u} /$ tend toward the periphery of the vowel space, the majority form an undifferentiated central configuration. This supports the already documented feature cf vowel neutralisation in the speech of the hearing impaired. It is therefore not possible to delineate any clear vowel space preoperatively. 
ary

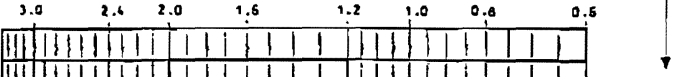

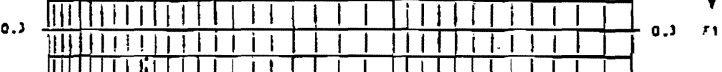

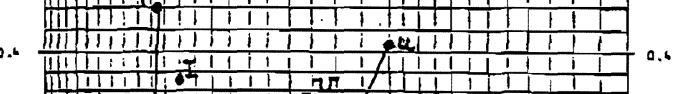

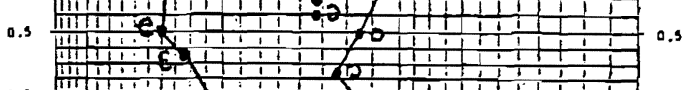

0.6

iil-1111101110

0.0

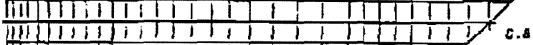

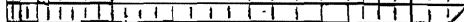

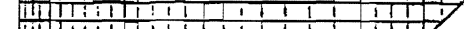

1.0

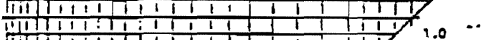

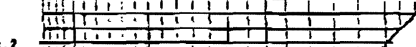

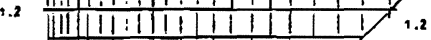

IIIIII! III!

Ii1 1111111

1.6 IIi

IIII) I: 1 , 1.6

III) 1

2.0 IIIfमा1)

1.0 2.6

Figure 1: The target vowel system

xhr



Figure 2: $\quad K$ 's preoperative vowel system 


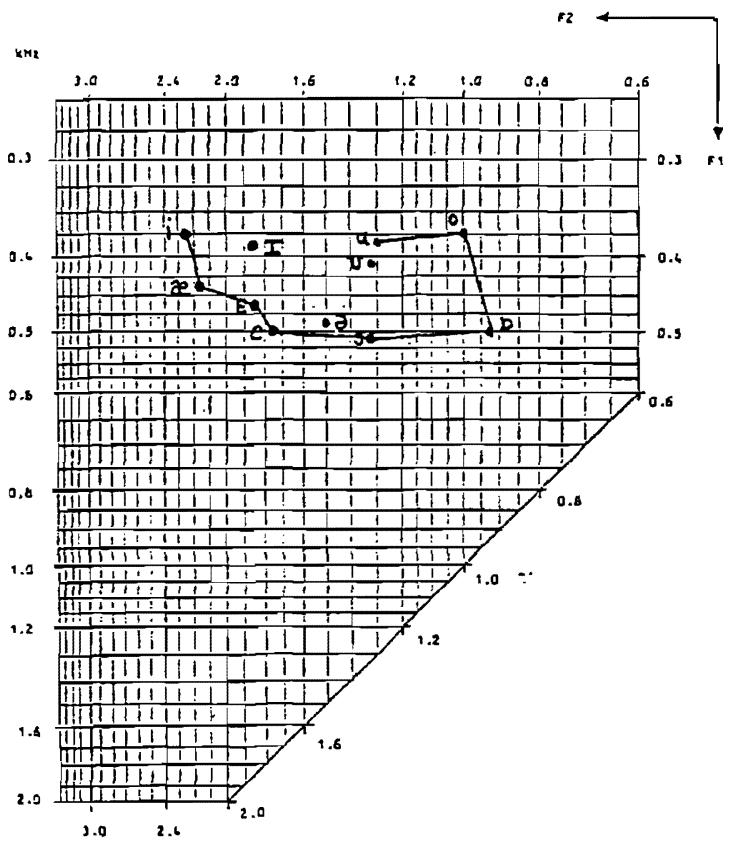

Figure 3: K's vowel system 6 months postoperatively

knz
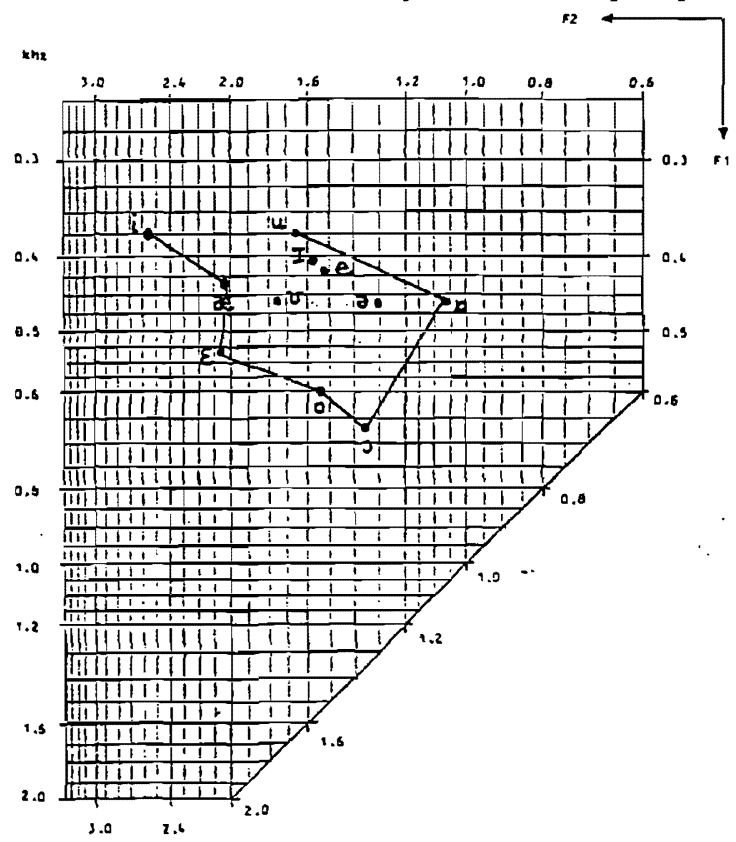

Figure 4: K's vowel system 1 year postoperatively 
The results 6 months postoperatively show a more expanded and more clearly defined vowel space with clearer differentiation among the vowel formants. In addition, the central vowels $/ \partial /, / I /$ and. $/ \mho /$ maintain a central position, while the other vowels assume a more peripheral position even though vowel height is somewhat indefinite. The results 1 year postoperatively differ marginally from-those of the analysis at 6 months, but show that the formant vowel space values remain more clearly discriminated now than at the preoperative evaluation.

Thus, the graphs for the post-implant formants indicate a development from a somewhat undifferentiated, neutral system to a system where formants form discrete peripheral and central entities which represent the vowels. Although the postoperative configurations may still be restricted, and only approximating to target values in some cases, there appears to be a development towards target values. The results also show that the developments remain in a state of flux as $\mathrm{K}$ 's perceptual and auditory monitoring skills develop under the stimulus of feedback. The evidence produced by the acoustic analysis is more richly indicative of changes than the evidence which can be gleaned from the AIT.

\section{(iii) Analysis according to part of Reid's Procedure for Assessing Vowels (unpublished)}

The contrastive analyses are presented in Appendices 3 - 5. The protocol consists of (a) a target system for SAE modified from Wells (1982), (b) correct or incorrect of K's vowel realisations in relation to the target system, in stressed and unstressed syllables and (c) an analysis of $K$ 's vowels in contrast with the monophthongs and diphthongs of the target system. It is this third, contrastive analysis which is being singled out for discussion here.

The target vowel system incorporated in this procedure is an adaptation of the one suggested by Wells (1982) for SAE vowels (Kemp, unpublished). Table 3 provides a summary of $\mathrm{K}$ 's vowel productions and reflects the respective frequencies of occurrence of correct and incorrect productions in relation to the target vowels. The most striking feature is the overall decrease in the number of errors and the corresponding increase of correct pronunciations or approximations to the target vowel. This trend is especially clear 6 months postoperatively. Progress in the correct realisation of $/ \mathrm{i} /, / \mathrm{I} /, / \mathrm{e} /, / \partial /, / \mathrm{l} /, / \mathrm{u} /$ and $/ \varepsilon I /$ is evident. The analysis shows no

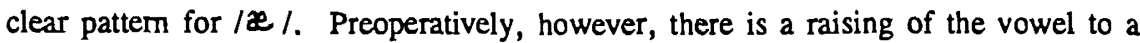


more $/ \varepsilon /$ - like quality. This particular result is evidence, it is suggested, of an instability in $\mathrm{K}$ 's vowel system. The $\mathrm{F} 1 / \mathrm{F} 2$ plots also present a confusing picture of the $/ e /-/ \varepsilon /-/ \not /$ configuration. The overall picture is encouraging, nevertheless, since it shows greater accuracy in K's attempts at producing the target vowels.

\begin{tabular}{|c|c|c|c|}
\hline Target Vowel & $\begin{array}{l}\text { Realisations } \\
\text { Preoperatively }\end{array}$ & $\begin{array}{l}\text { Realisations } \\
6 \text { months } \\
\text { Postoperatively }\end{array}$ & $\begin{array}{l}\text { Realisations } \\
1 \text { year } \\
\text { Postoperatively }\end{array}$ \\
\hline$i$ & $i(6) \partial(3) 3(1) v(1)$ & $i(10) I(1)$ & $i(10)=(1)$ \\
\hline I & $I(4) \partial(2)$ & $I(4) a(3)$ & $I(5) a(1) 3(1)$ \\
\hline e & $e(2) x_{y}(1)$ & $e(2) \varepsilon(1) u(1)$ & $e(3) i(1)$ \\
\hline$\varepsilon$ & $\varepsilon(3) e(1)$ & $\varepsilon(2) e(2)$ & $\varepsilon(3) e(1)$ \\
\hline$æ$ & $\mathrm{de}(5) \varepsilon(3) e(1) 3(1)$ & $\begin{array}{l}\partial e(3) \varepsilon(5) e(1) \\
\partial(1) 3(1)\end{array}$ & $\mathscr{a}(2) \varepsilon(6) e(1) 3(2)$ \\
\hline$e$ & $e(2) a(3)$ & $e(4) a(1)$ & $e(1) a(4)$ \\
\hline$D$ & $D(1) \wedge(1) a(2)$ & $p(3) P(1) a(1)$ & $D(2) e(1) a(1)^{\partial}(1)$ \\
\hline 0 & $2(3) \circ(3) \phi(1) 3 I(1)$ & $2(7) \circ(1)$ & $O(B)$ \\
\hline $0 / \partial v$ & $0 / 02(9)$ & $\begin{array}{l}0 / \partial v(5) v(1) \wedge v(1) \\
\wedge^{\circ}(1) \text { ev (1) }\end{array}$ & $0 / \partial v(7) \wedge v(1)$ o^(1) \\
\hline$u$ & $u(3) v(2) a v(1) \partial(1)$ & $u(5) v(1) y(2)$ & $u(5) v(1) I_{y}(1) \phi_{y}(1)$ \\
\hline$v$ & $\tau(1) a(1)$ & $v(0) a(1) 3(1) 30(1)$ & $v(0) \partial(2) 0(1)$ \\
\hline$\partial$ & $\partial(13) I(1) \wedge(1)$ & $\partial(13) I(1) e(1)$ & $\partial(15)$ \\
\hline 3 & - & - & - \\
\hline$\wedge$ & $\wedge(5) \approx(1)$ & $\wedge(5) \partial(1)$ & $\Lambda(5) \geqslant(1)$ \\
\hline$\varepsilon I$ & $\varepsilon I(5) \partial I(1)$ & $\varepsilon I(6)$ & $\varepsilon I(6)$ \\
\hline$\partial I$ & $a I(2) a(1)$ & $a I(1) a(1) e(1)$ & $a I(1) \wedge(1) e(1)$ \\
\hline JI & OI $(0) \rho(1)$ & $J I(0) \supset(1)$ & $O I(0) \partial(1)$ \\
\hline$\partial v$ & $\operatorname{ar}(0) a(2) \varepsilon(1)$ & $\operatorname{avg}(2) e(1)$ & $\partial v(1) e(2)$ \\
\hline ID & I $0(0) 3(1)$ & $I a(1)$ & $I \partial(0) J(1)$ \\
\hline va & - & - & - \\
\hline
\end{tabular}

Table 3: Summary of $\mathrm{K}$ 's realisations of target vowels and frequency of occurrence of errors 
The contrastive analysis reveals a decrease in the number of variations of $\mathrm{K}$ 's productions of most target vowels. There is also a progression towards greater differentiation and greater stability as $\mathrm{K}$ approximates to the adult system.

Examples of the vowels involved in this progression include $/ \mathrm{i} /, / \mathrm{o} /, / \partial /, / \mathrm{J} /$ and $/ \mathrm{u} /$. It appears that the spread of altemative pronunciations tightens into a more discrete system. This observation is supported by the acoustic analysis.

Based on several reports of improvements across a wide range of tasks, research has indicated that the benefits of cochlear implants are extensive (Busby et al 1989, Kessler 1989, Berliner et al 1989). The main aim of the present study was to determine whether there were changes in $\mathrm{K}$ 's vowel system at 6 months and 1 year interval post cochlear implant, and whether these changes reflected a progression towards a target vowel system for his dialect. It was hypothesised, considering the feature extraction facility of the Cochlear device, that K's vowel perception, and consequently his vowel production, should become more refined as he learns to interpret and use the information available to him.

The results quite clearly show definite changes in K's vowel system. It is particularly in the spectrographic analysis and phonological analysis according to Reid's procedure that the changes are noted.

Despite the restricted size of the sample, the spectrographic analysis shows that $\mathrm{K}$ 's vowel system developed from a somewhat undifferentiated and neutral one to a more clearly defined one, where vowels have discrete values which in some cases approximate to those of the target system. Osberger and McGarr (1982) observe that spectrographic analysis of hearing impaired speech is complicated by the additional harmonics introduced by factors such as nasality.

It is well known that F1 frequency is related to vowel height, and F2 to vowel backness (Di Benedetto 1989). Preoperatively, of course, $\mathrm{K}$ had no access to the information associated with these formants - a fact which partially explains the undifferentiated, neutral configuration of his preoperative vowels. Osberger and McGarr (1982) report that spectregraphic analysis of the vowels of deaf speakers shows that the formant frequencies tend towards those of the neutral vowel $/ \partial /$. Hearing impaired speakers, they conclude, use restricted tongue movements to achieve vowel differentiation. Since 
the cochlear implant is designed in part to extract the information about vowel differentiation from incoming acoustic signals and encode it, it is to be expected that after the implantation the vowel system will begin to demonstrate greater differentiation on these parameters. The results concerning $\mathrm{K}$ show that this is indeed what is taking place in his vowel system as he begins to make use of the auditory information newly available to him. K's variations between the 6 months and 1 year postoperative results could be related to changes in his abilities as he leams to utilise the incoming information.

Butcher (1982) states that no two speakers will produce identical formant frequencies, and this should be bome in mind when interpreting the variations and target vowels on the F1/F2 graphs. The vocal tract configurations are also influenced by preceding and following consonants. Despite these complications, the results of the present study seem to warrant the conclusion that the information which $\mathrm{K}$ is receiving from his cochlear implant has improved both his vowel perception and his vowel production, as shown by vowel differentiation on the F1/F2 plots.

The phonological analysis carried out in accordance with Reid's procedure (unpublished) provides further evidence for the conclusion of improved vowel production subsequent to implantation. Although the procedure was not originally intended for use with the deaf population, it is clear that its use is appropriate for this purpose. The error patterns recorded in the samples of the present study are similar to those documented in the literature for hearing children. Vowels which develop early in normal children and show high degrees of accuracy in phonologically disordered children are similar to those which develop stability in $\mathrm{K}$ 's system postoperatively (Stoel-Gammon \& Herrington 1990, Stoel-Gammon 1990, Hare 1983, Paschall 1983).

Hearing children with phonological disorder seem to experience similar difficulties with $/ \mathrm{e} /, / \varepsilon /$ and $/$ $/$ - a problem already identified in $\mathrm{K}$ 's evolving vowel system. It would be interesting to examine whether $\mathrm{K}$ 's vowels develop postoperatively along lines similar to those documented in the literature for hearing children.

The use of Reid's procedure requires some comment. Grunwell (1984:5) highlights several criteria for appropriate phonological assessment. She states that such a procedure should "provide the analytical techniques which identify the phonologically unacceptable and inadequate aspects of a child's pronunciation patterns". Furthermore, it is emphasised that the primary aim of such a procedure is to "state explicitly the patterns in the child's pronunciations and to indicate which of these patterns require 
modification in order to achieve more effective communication". Reid's procedure certainly provides the necessary framework to identify the segmental patterns in K's vowel system. The contrastive use of vowel phonemes and the identification of error patterns are essential steps in vowel remediation. The procedure also promises to be useful, in research and remediation, as a tool for monitoring changes and progress over time. The inclusion of the accent adaptable target system with which to compare the child's system is a unique and useful feature.

The three procedures used in the analysis of $\mathrm{K}$ 's data provide comparable results. However, the sensitivity of the types of analyses varies. While the spectrographic analysis may offer valuable information regarding the relationship between acoustic input and speech production, Reid's analysis is clinically useful. It was also shown that the use of AIT in isolation is not the most effective way to analyse data of this nature. The three procedures, it is therefore suggested, complement one another.

\section{CONCLUSION}

Despite the sample size, the longitudinal data presented in this investigation indicate that the Cochlear 22-electrode cochlear implant improves both vowel perception and vowel production, and that, in tum, this improvement enhances overall speech intelligibility.

The investigation draws attention to several remedial issues. The assessment and remediation of the vowels of phonologically disordered hearing impaired children should not be neglected. The potential contribution of vowel remediation to overall speech intelligibility appears to be underestimated. Furthermore, there are indications that direct intervention in the vowel systems of cochlear implant patients should prove successful if the patients are taught to optimise formant information and auditory feedback. 


\section{REFERENCES}

Amorosa, H., von Breda, U., Wagner,. E., and Keck, A. 1985. Transcribing phonetic detail in the speech of unintelligible children: a comparison of procedures. British Journal of Disorders of Communication (20) 281-287.

Berliner, K.K., Tonokawa, L.L., Dye, L.M., and Hause, W.F. 1989. Open-set Speech Recognition in children with a single-channel Cochlear Implant. Ear and Hearing (10) 4:237-242.

Bleile, K.M. 1989. A note on vowel patterns in two normally developing children. Clinical Linguistics and Phonetics (3) 2:203-121.

Busby, P.A., Tong, Y.C., Roberts, S.A., Altidis, P.M., Dettman, S.J., Blamey, P.J., Clark, G.M., Watson, R.K., Dowell, R.C., and Richards, F.W. 1989. Results for two children using a multiple-electode intracochlear implant. Journal Acoustical Society of America (86) 6:2088-2102.

Butcher, A. 1982. Cardinal Vowels and other problems in Crystal, D. (Ed). Linguistic controversies: Essays in linguistic theory and practice in honour of F. Palmer. Edward Arnold.

Clark, G.M., Busby, P.A., Roberts, S.A., Dowell, R.C., Tong, Y.C., Blamey, P.J., Nien huys, T.G., Mecklenburg, D.J., Webb, R.L., Pyman, B.C., and Franz, B.K. 1987. Preliminary Results for the cochlear Corporation Multielectrode Intracochlear Implant in Six prelingually Deaf Patients. The American Journal of Otology (8) 3.

Di Benedetto, M-G. 1989. vowel representation: Some observations on temporal and spectral properties of the first formant frequency. Journal of Acoustical Society of America (86) 1:55-66.

Eisenberg, L.S., Kirk, I.K., Thielemeir, M.A., Luxford, W.M., and Cunningham, J.K. 1986. Cochlear Implants in Children: Speech Production and Auditory Discrimination. Otolaryngologic clinics of North America (19) 2. 
Grunwell, P. 1985. Phonological Assessment of Child Speech (PACS). College Hill Press, San Diego.

Hare, G. 1983. Development at 2 years. In Irwin, J.V., and Wong, S.P. (Eds). Phonological Development in Children: 18 - 72 months. Southern Illinois University Press.

Kemp, M-A. 1990. Phonological Assessment. Procedures: Focus on Vowels. Unpublished paper. University of Reading.

Hodson, B.W. 1986. The Assessment of Phonological Processes - Revised. Inter state Printers and Publishers, Inc.

Kessler, D.K. 1989. Present Status of Cochlear Implants in Children. In Owens, E., and Kessler, D.K. (Eds). Cochlear Implants in Young Deaf Children.

Kirk, K.I., and Hill-Brown, C. 1985. Speech and Language Results in Children with a Cochlear Implant. Ear and Hearing (6) 3:365-475.

McGarr, N.S. 1986. The intelligibility of deaf speech to experienced and inexperienced listeners. Journal of Speech and Hearing Research (26) 451-458.

Oller, D.K., and Eilers, R.E. 1975. Phonetic Expectation and Transcription Validity. Phonetica (31) 288-304.

Owens, E., and Kessler, D.K. 1989. Cochlear implants in young deaf children.

Osberger, M.J. 1989. Speech production in profoundly hearing impaired children with reference to Cochlear Implants. In Owens, E., and Kessler, D.K. (Eds). Cochlear implants in young deaf children. College-Hill Press.

Osberger, M.J. \& McGarr, N.S. 1982. Speech production characteristics of the hearing impaired. In Lass, N. (Ed). Speech and Language: Advances in basic science and research. Academic Press N.Y. 
Paschall, L. 1983. Development at 18 months. In Irwin, J.V., and Wong, S.P. (Eds). Phonological Development in children: 18 - 72 months. Southern Illinois University Press.

Plant, G., and Öster, A-M. 1986. The effects of cochlear implantation on speech production: a case study. National Acoustic Laboratories, Sydney. Speech Transmission Laboratory Quarterly Progress and Status Report 65-86.

Pollock, K.E., and Keiser, N.J. 1990. An examination of vowel errors in phonologically disordered children. Clinical Linguistics and Phonetics (4) 2:161-178.

Pye, C., Wilcox, K.A., and Siren, K.A. 1988. Refining transcriptions: the significance of transcriber 'errors'. Journal of Child Language (15) 17-37.

Reid, J. 1989. A procedure for assessing vowels. Unpublished paper. University of Reading.

Roberts, S.A., Busby, P.A., Dowell, R.C., Clark, G.M., Tong, Y.C., and Mecklenburg, D.J. 1988. Initial experience with children using the Nucleus 22- Channel Cochlear Implant. Scandinavian Audiologic Supplement (30 115-119.

Rosen, S., Walliker, J., Bremacomber, J.A., and Edgerton, B.J. 1989. Prosodic and Segmental Aspects of Speech Perception with the House/3M SingleChannel Implant. Journal of Speech and Hearing Research (32) 93 111.

Shriberg, L.D., Kiwat Kowski, J., and Hoffman, K. 1984. A procedure for phonetic transcription by concensus. Journal of Speech and Hearing Research (27) 456-465.

Stoel-Gammon, C. 1990. Issues in Phonological Development and Disorders. In Miller, J. (Ed). Research on Child Language Disorders: A Decade of Progress. College-Hill Press, San Diego. 
Stoel-Gammon, C., and Herrington, P.B. 1990. Vowel Systems of normally developing and phonologically disordered children: Clinical Linguistics and Phonetics (4) 2:145-160.

Weismer, G. 1984. Acoustic Analysis Strategies for the Refinement of Phonological Analysis. In Elbert, M., Dinnsen, D., and Weismer, G. (Eds). Phonological Theory and the Misarticulating Child, ASHA Monographs (22) 30-52.

Wells, J.C. 1982. Accents of English. Volume 1: An introduction. Cambridge University Press.

Wells, J.C. 1982. Accents of English. Volume 3: Beyond the British Isles. Cambridge University Press. 
Appendix 1: McGarr Words - Vowel production preoperatively and 6 months and 1 year postoperatively

\begin{tabular}{|c|c|c|c|c|}
\hline Stimulus & $\begin{array}{l}\text { Target } \\
\text { Vowel }\end{array}$ & $\begin{array}{l}\mathrm{K} \\
\text { preoperatively } \\
6 \text { months }\end{array}$ & $\begin{array}{l}\mathrm{K} \\
\text { postoperatively } \\
1 \text { year }\end{array}$ & $\begin{array}{l}\text { K } \\
\text { postoperatively }\end{array}$ \\
\hline KEEP & {$[\mathrm{i}:]$} & {$[i:]$} & {$[i:]$} & {$[i:]$} \\
\hline READ & {$[i:]$} & {$[\tilde{3}]$} & [ijijI] & {$[i j i]$} \\
\hline WITH & {$\left[\frac{I}{v}>\right]$} & {$[\hat{\partial}]$} & {$[\hat{\partial}]$} & {$[\hat{A}]$} \\
\hline DOG & {$[\hat{D}]$} & {$[\partial د]$} & {$[e]$} & {$[D]$} \\
\hline HAIR & {$[\hat{\varepsilon}:]$} & {$[\tilde{\varepsilon}$ ] } & {$\left[\widetilde{\varepsilon}^{2}\right]$} & {$[\varepsilon:]$} \\
\hline GOOD & {$[v<]$} & {$\left[\Lambda^{v}\right]$} & {$[3:]$} & {$\left[0^{2}\right]$} \\
\hline CAT & {$[\hat{\mathrm{de}}]$} & {$[E<]$} & {$[\hat{\varepsilon}>]$} & {$\left[3^{\wedge}\right]$} \\
\hline NAME & [EI ] & 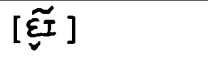 & [EI] & 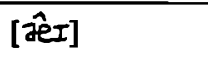 \\
\hline COAT & {$[0<]$} & {$\left[o^{v}\right]$} & {$[8 v]$} & {$\left[0^{2}\right]$} \\
\hline BALL & {$\left[0^{\wedge}\right]$} & {$\left[0^{2}\right]$} & {$\left[0^{2}\right]$} & {$\left[0^{2}\right]$} \\
\hline TEETH & {$[\dot{t}]_{\ldots}$} & [i:] & {$[i:]$} & {$[i:]$} \\
\hline MORE & {$\left[0^{\wedge}\right]$} & {$\left[0^{v}\right]$} & {$[03]$} & {$[0]$} \\
\hline MAN & {$[\hat{e}]$} & [ $\left.\widetilde{3^{x y}}\right]$ & {$[\widetilde{\varepsilon}:]$} & 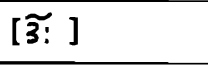 \\
\hline WISH & {$[I<]$} & [ a ] & [a] & {$[\hat{a}]$} \\
\hline FOOD & {$[*:]$} & [tt:] & {$[y<]$} & [iy:] \\
\hline RED & {$\left[e^{v}\right]$} & {$[\infty y]$} & {$\left[t^{2}\right]$} & {$\left[\widetilde{e}_{v}\right]$} \\
\hline PIECE & {$[i]$} & {$[\tilde{a}]$} & [i: ] & {$[\tau:]$} \\
\hline DEEP & {$[i:]$} & {$[i:]$} & {$[i:]$} & {$[\tau:]$} \\
\hline FEED & {$[i:]$} & [i: ] & {$[i:]$} & {$\left[\begin{array}{ll}i & 1\end{array}\right]$} \\
\hline HAVE & {$[\hat{\not}]$} & [ $\hat{\partial e}]$ & {$[\underset{\wedge}{\varepsilon}]$} & {$\left[\varepsilon_{\lambda}\right]$} \\
\hline DID & {$[I<]$} & {$[\hat{z}]$} & [ $\hat{\theta}$ ] & {$\left[3^{\wedge}\right]$} \\
\hline NEED & {$[i:]$} & & & \\
\hline CAKE & [ $\varepsilon I]$ & [हुI] & [ $\varepsilon I]$ & [ $\left.\varepsilon_{V} I\right]$ \\
\hline
\end{tabular}


Appendix 1: (continued)

\begin{tabular}{|c|c|c|c|c|}
\hline Stimulus & $\begin{array}{l}\text { Target } \\
\text { Vowel }\end{array}$ & $\begin{array}{l}\mathrm{K} \\
\text { preoperatively } \\
6 \text { months }\end{array}$ & $\begin{array}{l}\mathrm{K} \\
\text { postoperatively } \\
1 \text { year }\end{array}$ & $\begin{array}{l}\text { K } \\
\text { postoperatively }\end{array}$ \\
\hline HIS & [IL] & {$[\hat{I}]$} & [I] & [I] \\
\hline WILL & {$\left[I_{v}\right]$} & {$[a]$} & {$[a]$} & {$[\partial]$} \\
\hline THAT & {$[\hat{\partial e}]$} & {$\left[\varepsilon^{\wedge}\right]$} & {$[\varepsilon]$} & {$[\varepsilon]$} \\
\hline HAS & {$[\hat{\mathscr{E}}]$} & {$[\hat{x}]$} & [3:] & {$[\tilde{a e}]$} \\
\hline THIS & {$[I \geq]$} & {$[i]$} & $\left.\left[I^{2}\right)\right]$ & {$\left[\begin{array}{l}2 \\
0\end{array}\right.$} \\
\hline HEAR & [IO] & [3:] & [Ie] & {$[\partial>]$} \\
\hline COULD & {$[v]$} & {$\left[a p^{2}\right]$} & {$\left[3^{\circ}\right]$} & {$[\partial]$} \\
\hline BOOK & {$[v]$} & {$\left[\begin{array}{l}\hat{\partial} \\
a\end{array}\right]$} & [a & {$\left[\begin{array}{l}2 \\
2\end{array}\right]$} \\
\hline WAS & {$[\hat{p}]$} & {$[a]$} & {$\left[a^{v}\right]$} & {$[e]$} \\
\hline COOL & {$[t:]$} & [uw] & {$\left[y^{2}\right]$} & {$[\tilde{\phi} \tilde{y}]$} \\
\hline FAT & [ae ] & {$[\mathrm{e}]$} & {$[\hat{\varepsilon}]$} & {$[\varepsilon]$} \\
\hline FALL & {$[\hat{\jmath}]$} & {$[\phi w]$} & {$\left[0^{2}\right]$} & [ o ] \\
\hline BEACH & {$[i:]$} & {$\left[i^{i} t\right]$} & [iji] & {$[\tilde{\imath}]$} \\
\hline
\end{tabular}


Appendix 2: Summary of Hodson Words preoperatively and 6 months and 1 year postoperatively

\begin{tabular}{|c|c|c|c|c|}
\hline Stimulus & $\begin{array}{l}\text { Target } \\
\text { Vowel }\end{array}$ & $\begin{array}{l}\mathrm{K} \\
\text { preoperatively } \\
6 \text { months }\end{array}$ & $\begin{array}{l}\text { K } \\
\text { postoperatively } \\
\text { I year }\end{array}$ & $\begin{array}{l}\text { K } \\
\text { postoperatively }\end{array}$ \\
\hline BASKET & {$\left[\begin{array}{c}\hat{e}] \\
{[t v]}\end{array}\right.$} & {$\left[\begin{array}{l}a \hat{k} \\
\partial\end{array}\right]$} & {$\left[\begin{array}{c}E \\
t v\end{array}\right]$} & {$\left[\begin{array}{l}a \\
2\end{array}\right]$} \\
\hline BOATS & {$[0<]$} & [av] & {$[10]$} & {$[\wedge 0]$} \\
\hline CANDLE & {$\left[\begin{array}{l}\not \hat{E} \\
\partial\end{array}\right]$} & {$\left[\begin{array}{l}\widetilde{a p} \\
\partial]\end{array}\right]$} & {$\left[\begin{array}{c}\tilde{z e}: \\
\partial]\end{array}\right]$} & {$\left[\begin{array}{l}\tilde{E} \\
\partial\end{array}\right]$} \\
\hline CHAIR & {$\left[\varepsilon^{12}\right]$} & {$[\varepsilon:]$} & {$\left[\varepsilon^{\wedge}:\right]$} & {$\left[\varepsilon_{\Lambda}:\right]$} \\
\hline $\begin{array}{l}\text { COWBOY } \\
\text { HAT }\end{array}$ & $\begin{array}{l}{\left[\begin{array}{l}\partial v \\
{\left[\partial^{2}\right.}\end{array}\right]} \\
{\left[\partial^{\wedge}\right]}\end{array}$ & $\begin{array}{l}{\left[\begin{array}{l}a^{n} c \\
\tilde{5} \\
{[} \\
\varepsilon\end{array}\right]} \\
{\left[\begin{array}{l}0 \\
{[}\end{array}\right]}\end{array}$ & {$\left[\begin{array}{l}{\left[\begin{array}{l}a^{v} \\
\tilde{\sigma} \\
{[}\end{array}\right]} \\
\varepsilon\end{array}\right]$} & 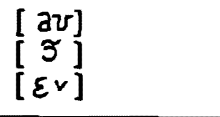 \\
\hline CRAYONS & $\begin{array}{l}{\left[\begin{array}{l}\varepsilon I] \\
{[} \\
0\end{array}\right]}\end{array}$ & $\begin{array}{l}{[\varepsilon I]} \\
{[\tilde{\sigma}]}\end{array}$ & {$\left[\begin{array}{l}\varepsilon I \\
0\end{array}\right]$} & {$\left[\begin{array}{l}\tilde{\varepsilon I}] \\
{[\tilde{J}]}\end{array}\right.$} \\
\hline THREE & {$\left[i:{ }^{\prime}\right]$} & [ $\tilde{a}]$ & {$[\tilde{\tau}]$} & {$[i j i]$} \\
\hline BLACK & [ $\hat{d e}]$ & [ $\hat{\mathscr{E}}]$ & [ $\varepsilon]$ & {$\left[\varepsilon_{v}\right]$} \\
\hline GREEN & {$[i v, j]$} & {$[i:]$} & {$[i:]$} & {$[i:]$} \\
\hline YELLOW & $\begin{array}{l}{\left[\varepsilon^{\wedge}\right]} \\
{\left[{ }^{\partial} O^{\wedge}\right]}\end{array}$ & {$\left[\begin{array}{l}e \\
a \\
a\end{array}\right]$} & {$\left[\begin{array}{ll}e & e \\
0^{2}\end{array}\right]$} & $\begin{array}{l}{\left[\begin{array}{l}e \\
{[} \\
0^{2}\end{array}\right]} \\
\end{array}$ \\
\hline FEATHER & {$\left[\begin{array}{l}e \\
{\left[\begin{array}{l}a\end{array}\right]}\end{array}\right.$} & {$\left[\begin{array}{l}e \\
{[a}\end{array}\right]$} & {$\left[\begin{array}{l}e \\
a\end{array}\right]$} & {$\left[\begin{array}{l}e \\
z\end{array}\right]$} \\
\hline FISH & {$[I<]$} & [I] & [ I ] & [ I ] \\
\hline FLOWER & $\begin{array}{l}{[a v]} \\
{[a]}\end{array}$ & {$\left[\begin{array}{l}e \\
e \\
a\end{array}\right]$} & {$\left[\begin{array}{l}\partial v] \\
{[\partial]}\end{array}\right.$} & $\begin{array}{l}{[a v]} \\
{[\partial]}\end{array}$ \\
\hline FORK & [ O^] & [3I] & [ ว: ] & {$[0<]$} \\
\hline GLASSES & {$\left[\begin{array}{l}e \\
\dot{t}\end{array}\right]$} & {$\left[\begin{array}{l}a: \\
{[a}\end{array}\right]$} & {$\left[\begin{array}{l}e:] \\
{[a]}\end{array}\right.$} & {$\left[\begin{array}{l}a \\
a \\
z\end{array}\right]$} \\
\hline GLOVE & $[\partial\rangle]$ & {$[\partial]$} & {$[\partial>]$} & {$[\wedge]$} \\
\hline GUM & {$[\partial>]$} & {$[\wedge]$} & {$[\partial د]$} & {$[\wedge]$} \\
\hline
\end{tabular}


Appendix 2: (continued)

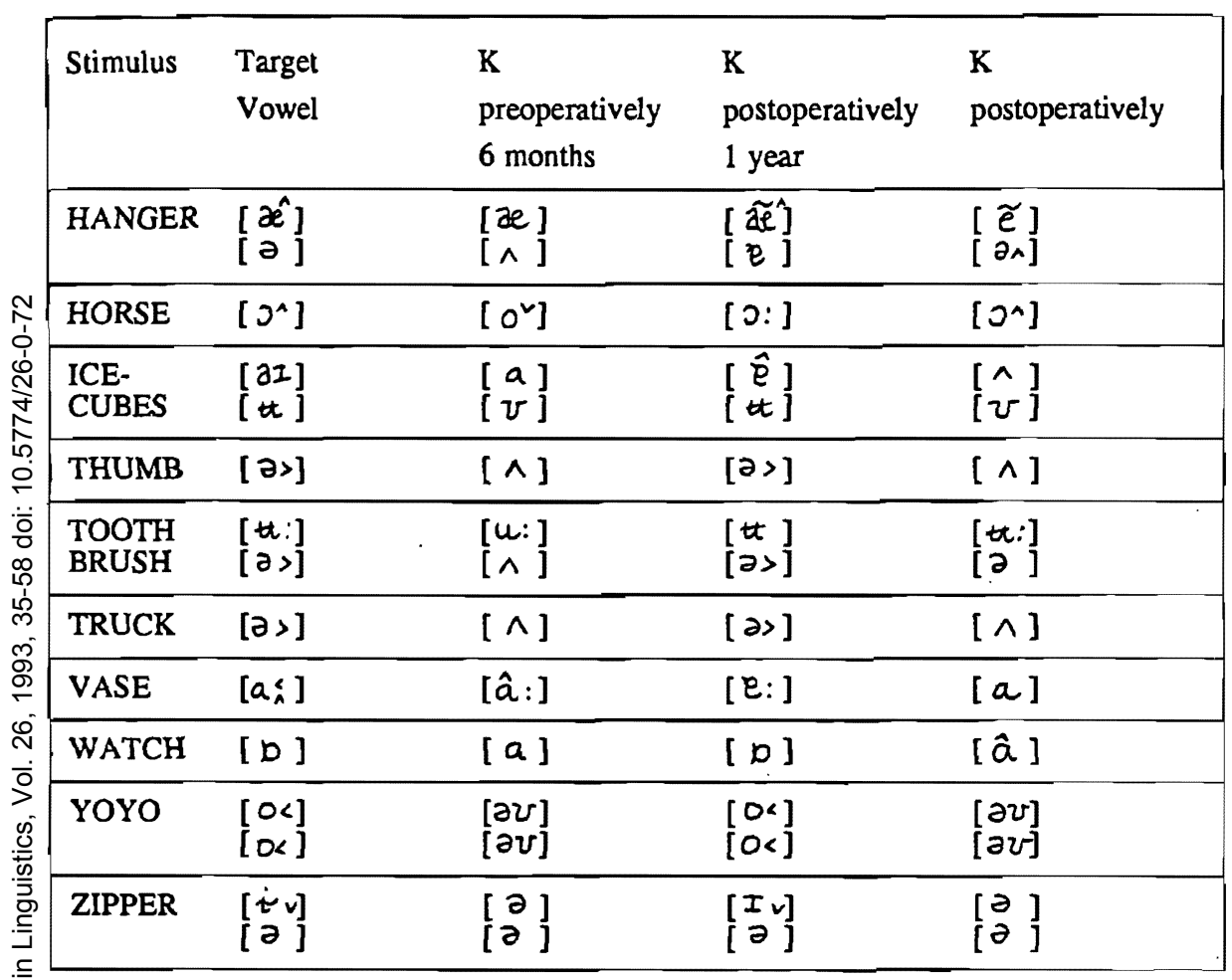


Appendix 3: Contrastive analysis of $K$ 's vowels preoperatively

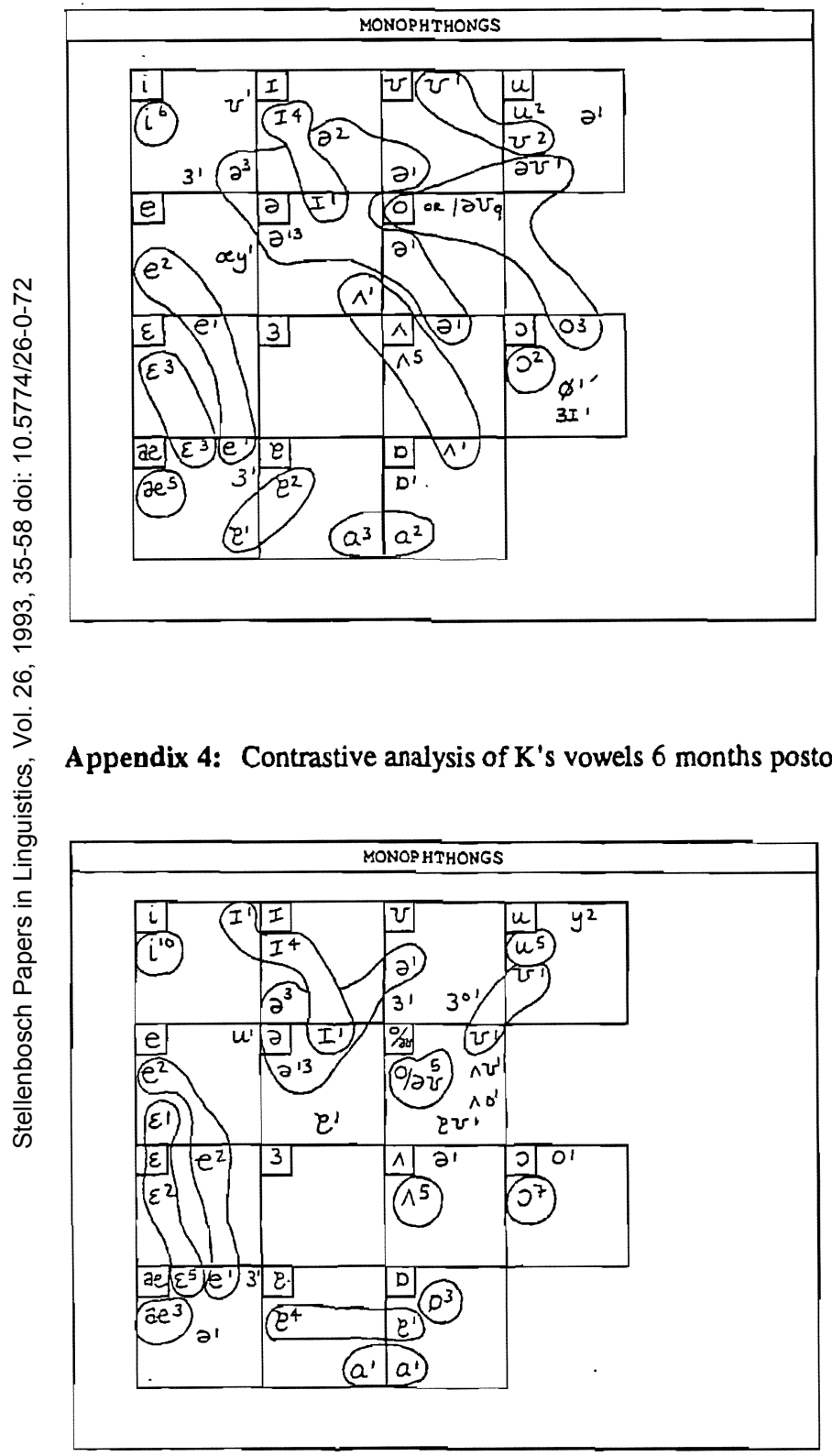


Appendix 5: Contrastive analysis of $\mathrm{K}$ 's vowels 1 year postoperatively

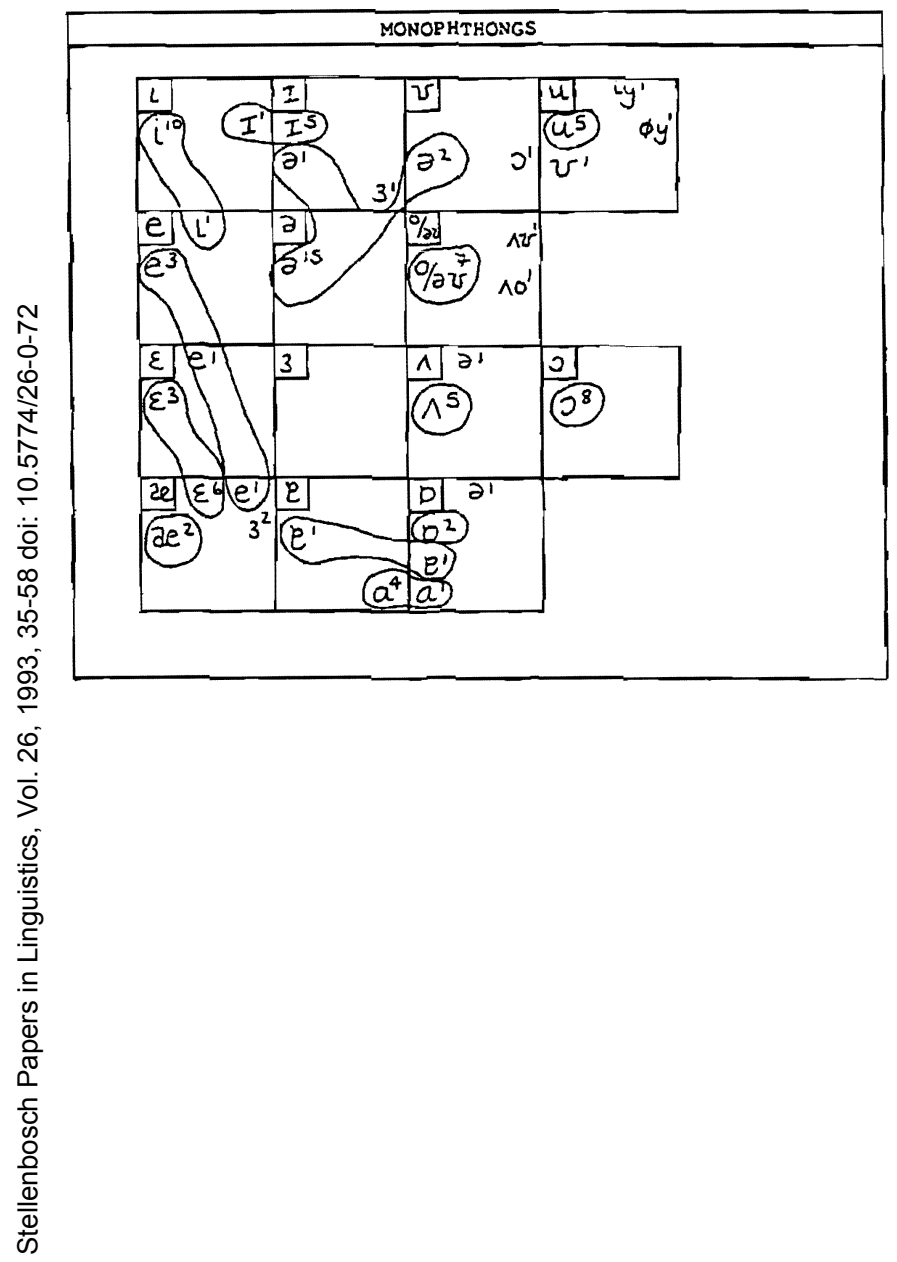

